Original article

\title{
A study on assessment of ASHA's work profile in the context of Udupi Taluk, Karnataka, India
}

\author{
Swathi Shet, Kumar Sumit*, Sameer Phadnis \\ Prasanna School of Public Health, Manipal University, Karnataka, India
}

\section{A R T I C L E I N F O}

\section{Article history:}

Received 27 July 2017

Accepted 22 August 2017

Available online 1 September 2017

\section{Keywords:}

ASHA

Knowledge

Roles and responsibility

Challenges incentives

\begin{abstract}
A B S T R A C T
Accredited social health activist (ASHA) workers and their activity are considered as the one of the key component of National Health Mission (NHM). ASHA workers serves as an important link between community and the health facilities.

Objective: To assess the knowledge and practice of ASHA workers regarding their roles and responsibilities and to study the challenges faced by them.

Method: A cross sectional study was conducted in health care centers of Udupi Taluka, Karnataka with 100 ASHA workers for Quantitative and 10 for Qualitative.

Result: The study revealed that the knowledge of the ASHA workers on ANC and PNC (82\%) is considerably higher than the knowledge on Family planning (71\%), Child health (65\%) and General health (67\%). 80\% had expressed their dissatisfaction towards incentives and other working conditions

Conclusion: The overall knowledge of ASHA workers was sufficient in the field of MCH but there is a need for mitigation of few key challenges, which would significantly contribute to improvement of ASHA's work profile.
\end{abstract}

(C) 2017 Published by Elsevier, a division of RELX India, Pvt. Ltd on behalf of INDIACLEN.

\section{Introduction}

A new initiative was undertaken in the Indian health care system by introducing Accredited Social Health Activist (ASHA) workers under the aegis of National Health Mission (NHM) instituted by the Ministry of Health and Family welfare, Government of India in year 2005..$^{1,2,3} \mathrm{NHM}$ is the principal program of the Government to achieve MDGs goal such as MMR, IMR, as well as control of specific diseases and improve the nutritional status of children and mother and to mainly improve the accessibility, availability and acceptability of health facilities particularly in the rural areas. ${ }^{4,5}$

ASHA is a village level female health worker as well as promoter of healthy practices. As of July 2013 the total number of ASHA's in India was $8,70,089 .{ }^{7}$ She serves for the population of 700 in tribal areas or 1000 in rural villages. ${ }^{1,2}$

The Sample registration system report published in the year 2013 reported that there were 40/1000 live births of Infant Mortality Rate (IMR) in the urban and 51/1000 live births in a rural area, whereas 167/100000 live births were the Maternal Mortality

\footnotetext{
* Corresponding author.

E-mail address: sumitsharma315@gmail.com (K. Sumit).
}

Ratio (MMR) (2011-13) ${ }^{6,10}$. Data shows poor condition of Maternal and child health in India. In order to reduce the MMR and IMR in India, Government of India launched the an umbrella program famously called National Rural Health Mission (Now called as National Health Mission-NHM) on 5th April 2005, with a new group of community level health workers named as Accredited Social Health Activist (ASHA) as its key implementing force at the ground level. The Ministry of Health \& Family Welfare (MOHFW) has developed a basic training module to provide the necessary knowledge and skills to women identified as ASHAs and there are also regular re-orientation training programs organized at the district levels. Separate curriculum and training facilities are made available in to equip ASHAs with adequate skills., ${ }^{9,11}$

Earlier Studies have reported gaps in the linkage between Government Health system and the communities resulting in confusion about their roles and responsibilities. In general incomplete knowledge and inconsistent financing will ultimately lead to a greater chance of ASHAs being unwilling to participate actively in the health programs. Twelve years down the line, it is necessary to assess the overall work profile of the ASHA workers and their worries to get their inputs for future course corrections. Therefore it is necessary to keep the ASHA worker motivated and to oversee that they are satisfied to perform their roles and 
responsibilities effectively and efficiently and also it is imperative to address the challenges and issues faced by them.

Therefore the current study was undertaken to get an in-depth information about the ASHAs work profile and their overall working conditions in Udupi Taluk. The findings from this study will be really helpful to identify the gaps pertaining to working profile of ASHAs and it can be used as take-home message for further improvisation.

\section{Methods}

A Prospective cross sectional study was conducted from January 2017-July 2017, using both quantitative and qualitative method in Udupi Taluk of Udupi district, Karnataka. Currently Udupi Taluk comprises of 268 ASHA workers approximately and each of them covers a population of 1000 population each. This study was conducted among selected ASHA workers of 14 selected PHC and one CHC. Quantitative data was collected among NHM appointed ASHA workers, present on the day of interview, who has completed at least 365 days of service by November 2016 and were willing to participate in the study. The Qualitative data was collected from the ASHA facilitators of selected health centers with the same inclusion criteria.

This study was conducted using 2 stage sampling technique. In the first stage random selection of Health centers were conducted out of 22 PHC and 3 CHC. Fifteen health centers (14 PHC and $1 \mathrm{CHC}$ ) were selected by using simple random selection technique. Second stage was to select ASHA workers from these randomly selected health centers. 100 ASHA workers were selected by using probability proportionate sampling and were interviewed using a self-designed semi structured questionnaire. Ten in-depth interviews were conducted among ASHA facilitators, which lasted for an average of 35-45 min. The qualitative interviews continued till information saturation was achieved. Written informed consent was taken from all the participants before the interview. The questions were focused mainly on the themes- regarding ASHAs roles and responsibilities, duties, challenges and training given to them as part of their work.

The study was approved from Institutional ethics committee (IEC) on 14 th December 2016. Confidentiality and anonymity of the respondents was maintained throughout the study. Qualitative data was analyzed using descriptive statistics like proportions and percentages by using SPSS-16. Thematic analysis was done for the Qualitative data.

\section{Results}

Table 1 demonstrates that majority of the ASHA workers are falling under the age group $41-50$, where almost $52 \%$ of the ASHA workers are aged above $41-50$ years and $41 \%$ of them are of $31-40$ age group. This distribution is due to the fact the current study focused only one experienced ASHA workers during data collection. Majority of the ASHA workers (65\%) have finished secondary level of education.

$60 \%$ of the ASHA workers hail from joint family. $88 \%$ of them have household income of 10-25 thousands per year and all of them are BPL card holders. Among 100 ASHA workers 90\% were working in the same village of residence. And 3\% of the ASHA workers had a child aged below 5 years old.

Table 2 showing that $69 \%$ of the ASHA workers were covering the population size from $1000-1500$, other than this $9 \%$ of the ASHA worker were having $1500-2000$ population. Majority (94\%) of the ASHA workers were covering single village, whereas $6 \%$ were expected to cover more than 2 villages.
Table 1

Distribution of the ASHA workers according to the socio- demographic profile $(\mathrm{n}=100)$.

\begin{tabular}{lcc}
\hline Age of Participants & Count $(\mathrm{n})$ & Percentage $(\%)$ \\
\hline $21-30$ & 4 & 4.0 \\
$31-40$ & 41 & 41.0 \\
$41-50$ & 52 & 52.0 \\
$51-60$ & 3 & 3.0 \\
Marital Status & 100 & 100 \\
Married & Count $(\mathrm{n})$ & Percentage $(\%)$ \\
Education & 15 & 15.0 \\
Primary & 65 & 65.0 \\
Secondary & 19 & 19.0 \\
Pre-University & 1 & 1.0 \\
Graduation & & 88.0 \\
House Income (In Thousands) & 88 & 10.0 \\
$10-25$ & 10 & 1.0 \\
$26-50$ & 1 & 1.0 \\
$51-75$ & 1 & 40.0 \\
$76-100$ & & 60.0 \\
House type & 40 & 90.0 \\
Nuclear & 60 & 10.0 \\
Joint & & 3.0 \\
Working in same village of residence & 90 & 97.0 \\
Yes & 10 & \\
No & 3 & \\
Having child aged below 5 years & 97 & \\
Yes & & \\
No & & \\
\hline
\end{tabular}

Table 2

Distribution of the Duties of ASHA workers.

\begin{tabular}{lcc}
\hline POPULATION SIZE & COUNT $(\mathrm{n})$ & PERCENTAGE $(\%)$ \\
\hline $800-1000$ & 20 & 20.0 \\
$1001-1500$ & 69 & 69.0 \\
$1501-2000$ & 9 & 9.0 \\
$2001-2500$ & 2 & 2.0 \\
No. of villages covered & 94 & \\
One & 5 & 94.0 \\
Two & 1 & 5.0 \\
Three & & 1.0 \\
No. of house visits conducted & 61 & \\
$0-100$ & 33 & 61.0 \\
$101-200$ & 6 & 33.0 \\
$201-300$ & 7 & 6.0 \\
No. of hours of field visit (hrs.) & 89 & 7.0 \\
$0-2.30$ & 4 & 89.0 \\
$2.30-5$ & & 4.0 \\
$5-70.30$ & & \\
\hline
\end{tabular}

\subsection{Total number of birth and pregnancy registration by ASHA workers}

Out of 100 ASHA workers (70\%) of them had registered between 0 and 100 no. of pregnancies and births. 17\% \& 19\% of the ASHA workers reported that they had registered 101-200 pregnancies and births throughout their work experience. Only $2 \%$ and $4 \%$ had reported more than 400 pregnancies and births till the date of interview.

\subsection{Knowledge on ANC and PNC}

$80 \%$ of the ASHA workers were aware about the importance of Vitamin and iron supplementation during pregnancy. 93\% of the ASHA agreed that the initial breast milk was very important for the new born. Also $86 \%$ had the knowledge that additional supplement should be given after 6 months of the delivery. Majority of ASHA workers were aware about the fact that exclusive breast feeding should be done up to 6 months (Table 3 ). 
Table 3

Knowledge on ANC and PNC.

\begin{tabular}{lcc}
\hline Vitamin/iron supplementation importance & Frequency & Percent \\
\hline Yes & 80 & 80.0 \\
No & 7 & 7.0 \\
Don't know & 13 & 13.0 \\
Is colostrum important? & 93 & \\
Yes it is very important & 7 & 93.0 \\
Yes, but discard first few drops & & 7.0 \\
Additional supplement necessity & 14 & \\
No, up to 3 months & 86 & 14.0 \\
No, up to 6 months & & 86.0 \\
Period of exclusive Breast feeding & 4 & \\
3months & 71 & 4.0 \\
6months & 14 & 71.0 \\
9months & 11 & 14.0 \\
1year & & 11.0 \\
\hline
\end{tabular}

\subsection{Knowledge on child health}

The knowledge of ASHA worker on child health, in this study most of the ASHA workers i.e., 85\% were aware that evil spirit will not effect on the health of the child. Majority (61\%) of the ASHA workers have the knowledge that DPT vaccine has the side effect in form of mild fever. Almost 69\% of the ASHA workers were stated that in case of high fever, immunization should be postponed. Majority (47\%) of the ASHA workers knew about the prevention of risk of diarrhea.

\subsection{Knowledge on family planning}

(83\%) of the ASHA workers were aware that Oral contraceptives was not used during breast feeding. Also 93\% of ASHA suggested that new condom should be used for each sexual act. About $44 \%$ of the ASHA workers were unaware that ECP are not effective even 1 week after unprotected sex. Majority (67\%) of the ASHA's had the knowledge that tubectomy/vasectomy was the best contraceptive method of family planning.

\subsection{Knowledge on general health}

Majority (49\%) of ASHA workers knew about the factors responsible for the spread of HIV-AIDS. $46 \%$ had reported that they refer TB suspected patients to the PHC. Almost 93\% knew about first aid for dog bite. The majority (83\%) were agreed that mental illness has cure.

\subsection{Practice of ASHA workers regarding their roles and responsibilities}

Majority (97\%) of ASHA worker reported that they were informing to the health centers about birth and deaths in the village and outbreak of diseases. ASHA workers was expected to fill the records documenting vital events, most (55\%) of the ASHA workers were remembered that they were filling 3-6 records, where $35 \%$ were filling $7-10$ records followed by $10 \%$ people were filling 11-14 numbers of records. Majority (46\%) of them were aware about the ideal time for the hand wash. Also 77\% of the ASHA workers were having knowledge on sending children's to the Anganwadi center was from 3 yrs of age.

\section{Challenges faced by ASHA workers}

Activity based incentives was the main challenge faced by ASHA worker. Where majority (95\%) of the ASHA workers agreed that they are getting monthly incentives by the Government, along with that they also mentioned that, only monthly incentives were paid according to their activity but not the monthly salary. $83 \%$ respondents complained that they were not given any compensation or reward for the best performance for their recognition of work by the Government. Majority (95\%) of ASHA workers had agreed that they are given compensation for attending trainings. And $88 \%$ had shared that they are getting incentives through the ASHA mentor. Nearly half (41\%) of the ASHA workers had reported about delay in getting monthly incentives.

Majority (26\%) of the ASHA workers reported that they were earning $2000 /-$ per month, $22 \%$ of the respondents reported that they were earning 1500 rs per month and $15 \%$ had reported that they were earning 1200 rs per month. Highest earning was reported by $3 \%$ of ASHA workers whereas $7 \%$ reported lowest earnings.

\subsection{Assessment of the working condition of ASHA workers}

Majority (69\%) of the ASHA reported that challenges in case of any queries regarding the patients were solved mainly by the ANMs and 30\% had mentioned Medical officer MO addressing their issues. In case of queries regarding pregnant mothers (63\%) of the ASHA reported that they contact ANM, and few (29\%) also stated MO. In case of queries regarding incentives $83 \%$ of the ASHA workers had reported to approach ASHA mentors for the same

\subsection{Qualitative data analysis}

\subsubsection{Family factors that affects the profile of ASHA worker}

Every ASHA selected by the community should be married and should reside in the same community. Being a family member and as an ASHA worker she plays both the roles. In this study I have found that most of the ASHA workers said that their husband was their main strength, as he supports all the time which made their work easy.

\subsubsection{Psychological factors affecting ASHA'S work profile}

4.2.2.1. Dignity. Most of the ASHA had stated that working as an ASHA worker is a job, where they are treated with lots of respect. They are happy with the respect given by the community in recognition of their work.

4.2.2.2. Self-confidence. Most of the ASHA workers reported that, working as an ASHA worker helped them in improving their selfconfidence. After so many years of experience they are confident enough to counsel the community and encourage them to access and avail available health care services.

4.2.2.3. Over burden of work. Almost all the ASHA workers stated that the burden of work was overloading for them, because not only they are only the volunteers, they can't invest their full working hours only for the field works,

Few said that training sessions were hectic, for few filling records is the main burden and some also said that spending much time in the field in the sunny afternoon is the main challenge to them. In together working in each and every health program made them to feel sick

4.2.2.4. Satisfaction. All the ASHA workers had said that they are satisfied with their work but not about the incentives paid for them, they also reported that they were not paid according to their work. Majority of ASHA workers assume that the pay scale is fairly an injustice to the amount of work they do

4.2.2.5. Stress. Majority of the ASHA worker feels that walking in the afternoon, for the field visit is the main stress, whereas some of 
them were said that filling record was the stressful work, few reported that burden of work is the stressful factor affecting their work. Many ASHA workers had said that they feel it as more stressful work but they in hope of getting salary hiked one or other day which shows their helplessness towards their situation.

4.2.2.6. Learning opportunity. Majority of the ASHA workers were happy about their job, as they get to know lot of things, Most of them had said that it was a learning opportunity for them that is the reason for which they found this work was interesting.

\section{Opinion to improve the quality of ASHA workers}

\subsection{Demands of ASHA workers}

Almost all ASHA workers were demanding for monthly salary, health insurance and provident fund from the Government. Most of the ASHA workers were disappointed with the Government about activity based incentives, with the complaint that paid incentives were not fulfilling their needs, at least Government should pay according to the daily basis, and most of the people were demanding 200 Rupees per day as a daily wage. They believe that Governments paid incentives are not doing justice to their work.

\section{Discussion}

Majority of the ASHA workers were in the Age group of 31-40 years. Similar results were observed by studies conducted by Sharma R and Fathima FN et al. ${ }^{8}$ In this study it is also found that most of the ASHA workers have completed their secondary school of education, this shows that the selection criteria of the ASHA workers were as per the norms of NHM guidelines, which was also supported by study conducted by Fathima FN et al ${ }^{8}$ and Garg P et al. ${ }^{3}$. Study also provide information that more than half of ASHA workers have received drug kit, similar findings were supported by Garg P et $\mathrm{al}^{3}$. It is also expressed that availability of drug kit, builds confidence of community in ASHA workers as it of paramount importance in case of emergencies.

In this study knowledge on different aspects among ASHA workers were revealed, knowledge on child health was $65 \%$, which again has similarity with the findings from several previous studies. It is recorded that ASHA workers had good knowledge on ANC and PNC, similar finding is again recorded in Fathima FN et al and Garg P et al. And also it is found that many were lacking knowledge other than Maternal and Child Health, this fact was supported by Gosavi et al. ${ }^{12}$ The study also focused on training component of ASHA workers where it was found that training provided were intensive. The ASHA workers had a good knowledge about their roles and responsibilities as it was evident from their prompt participation in refresher trainings, performance in the field visit, participation in village health, nutrition day and participation in village health and sanitation committee meeting, attending meetings. In this study ASHA workers regularly complained about the over load of training sessions which was mentioned in the study by Kohli $\mathrm{C}$ et al ${ }^{14}$. The present study reveals that the most important demand of the ASHA workers were monthly salary in the place of activity based financial incentives. Many others have also reported that activity based incentives was one of the demotivating factors for them to perform in a longer run. ASHA workers also complaint about delay in paying incentives which is supported by studies conducted by Saxena $V$ et a, and Wang $\mathrm{H}^{11,13}$.

\section{Conclusion}

In the current study it was found that apart from the financial incentives, other challenges faced by ASHA workers are regular misunderstanding with the ANM's, family issues, transportation issues, social insecurity, lack of self-confidence and increasing work load as reported by some of the other previous studies. This study provided the information on factors influencing ASHA's work profile in Udupi Taluk with reference to their knowledge, practice and different training programs provided to them. It was concluded that the knowledge of the ASHA workers on ANC and PNC (82\%) is considerably higher than knowledge on Family planning (71\%). The ASHA workers exhibit average knowledge on child health (65\%) and General health (67\%). ASHA workers are satisfied by the teaching methods and training compensations provided in Training sessions, whereas most $(41 \%)$ of them felt that the training provided were excessive and $9 \%$ had share that the trainings were inadequate and few technical words were difficult to understand (Graph 1).

\section{Recommendation}

It's very much evident from the current study that there is a need for timely activity based incentives for the ASHA workers and to also look in their demand for regular monthly salary. The training module provided should be more of demonstration rather than theory. In future research can focused to get a deep insight on the motivating factors to improve the ASHA's performances.

\section{No. of registeration of pregnancy and births}

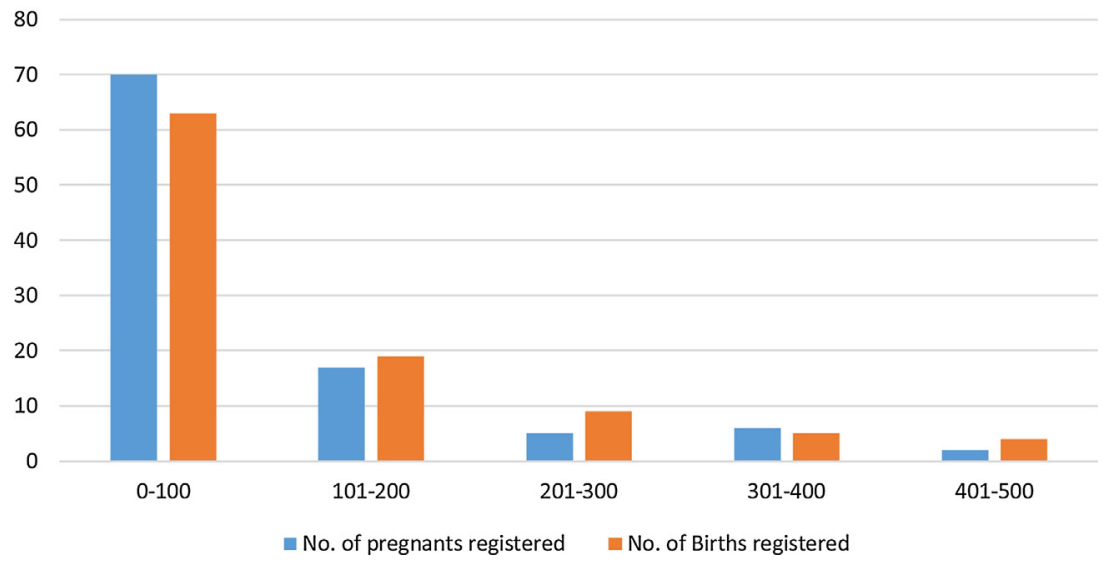

Graph 1. Total no. of birth and pregnancy registration by ASHA workers. 


\section{References}

1. Government of India. National Rural Health Mission-12), Mission Document. [Available at: http://www.mohfw.nic.in/NRHM/Documents/ Mission_Document.pdf. Accessed on 28 November 2016].

2. Sharma R, Webster P, Bhattacharyya S. Factors affecting the performance of community health workers in India: a multi-stakeholder perspective. Glob Health Action. 2014;7(1):1-8.

3. Garg PK, Bhardwaj A, Singh A, Ahluwalia SK. An evaluation of asha worker's awareness and practice of their responsibilities in rural Haryana. Natl J Community Med [Internet]. 2013;4(1; 2):020411-020480.

4. Kori S, Bhatia M, Mishra A. A Cross-sectional Assessment of Knowledge of ASHA Workers. J Krishna Instit Med Sci Univ. 2015;4(Octobe-December (4)).

5. Ministry of Health, Family Welfare. Government of India. Accredited Social Health Activist (ASHA) Guidelines. New Delhi: National Rural Health Mission; 2005 [Available from http://nrhm.gov.in/communitisation/asha/about-asha. html].

6. Kohli C, Kishore J, Sharma S, Nayak H. Are accredited social health activist workers aware of their roles and responsibilities. Int J Med Res Heal Sci. 2015;4 (3)616 [Availablefrom: http://www.indianjournals.co./ijor.aspx?target=ijor: ijmrhs\&volume=4\&issue $=3$ \&article $=026]$.
7. Roles T, Under R, In N, Karnataka R. Full Length Research Article Assessment of Knowledge of Accredited Social Health Activists (ASHA). REGARDING. 2015;5:3860-3862.

8. Fathima FN, Raju M, Varadharajan KS, Krishnamurthy A, Ananthkumar SR Mony PK. Fathima FN., et al. 2015. 2015;33(1):137-45.

9. India National Rural Health Mission. 6th Common Review Mission Report. New Delhi: National Rural Health Mission, Ministry of Health \& Family Welfare, Government of India; 2012:36-38.

10. Angadi MM. A study to evaluate the knowledge of ASHA workers on antenatal and postnatal care in Bijapur district. Int J Res Med Sci. 2015;3(9):2299-2302.

11. Saxena V, Kakkar R, Semwal VD. A study on ASHA -a change agent of the society. Indian J Community Heal. 2012;24(1):15-18.

12. Gosavi SV, Raut AV, Deshmukh PR, Meh endale AM. ASHA's Awareness \& Perceptions about Their Roles \& Responsibilities: A Study From Rural Wardha J Mahatma Gandhi. Inst Med Sci. 2011;1(16).

13. Wang H, Juyal RK, Miner SA, Fischer E. Performance-Based Payment System for ASHAs in India: What Does International Experience Tell Us? [March].

14. Kohli C, Kishore J, Sharma S, Nayak H. Are accredited social health activist workers aware of their roles and responsibilities. Int J Med Res Heal Sci [Internet]. 2015; [Availablefrom:http://www.indianjournals.com/ijor.aspx? target=ijor:ijmrhs\&volume $=4 \&$ issue $=3 \&$ article $=026]$. 